\title{
Tetra-parameter Fish Feeding Machine
}

\author{
Ertie Abana, Maureen Baricaua, Rochelle Joyce Casibang, Aldene Paulino Babaran, \\ Vincent Joseph Gaspar, Fritz Gerald Puzon \\ School of Engineering, Architecture and Information Technology Education \\ University of Saint Louis \\ Mabini Street, Tuguegarao City, Cagayan \\ Philippines
}

Received: October 18, 2020. Revised: November 30, 2020. Accepted: December 5, 2020.

Published: December 10, 2020.

\begin{abstract}
This study developed an automated machine that automatically controls the feeding routine of fish by checking four parameters that will serve as a prerequisite before dispensing the required amount of commercial feeds. The parameters to be checked are time, precipitation, the water temperature of the pond, and behavior of the fishes. The machine is also capable of notifying the owner or caretaker via text message if fishes have been fed successfully or not and if the level of the feeds is low. The machine utilizes sensors, namely a raindrop sensor, temperature sensor, and water flow sensor in which data are gathered through the aid of a microcontroller. After undergoing several trials, it was revealed that the fish feeding machine was able to implement the capabilities of the manual process of feeding done by a fish farmer. It also dispensed the required weight of feeds on time after satisfying the parameters. The machine was also reliable in terms of sending notifications to the owner through text message since results convey that they were received within 10 seconds if the signal is fine.
\end{abstract}

Keywords: - fish feeder, raindrop sensor, temperature sensor, water flow sensor, microcontroller, text message

\section{INTRODUCTION}

The world population is vastly increasing simultaneously with the demand for food products needed for survival. According to the annual report of the Food and Agriculture Organization of the United Nations (2018), aquaculture continues to be the fastest-growing food-producing sector in the world with a yearly growth rate of 5.8\% since 2010 . Moreover, it has been inferred that the world will consume 20\% more fish by 2030 than in 2016. Ranked at the tenth, the Philippines was one of the topmost producers worldwide in the aquaculture industry contributing 1, 865, 213 metric tons in the total production in the year 2018 .

In the industry of aquaculture, feed intake is a significant factor that confines production. So far, fish feeding is done manually and is considered time-consuming and laborious [1]. It has been generally based on artificial judgment and experience of the farmer. The problem with this is that it is not the fish, but the farmer who regulates satisfaction along with when and how often should aquatic animals be fed. Farmers may tend to miscalculate feed allocation. Less feeding may result in less growth; overfeeding may result in the waste of feed and low feed efficiencies, and both result in an economic loss [2]. At an actual fish farm, the fish are fed according to the feeding rate calculated based on the weight of the fish. However, the appetites of the fish may be affected by several factors such as dissolved oxygen, weather, and temperature and each feeding procedure may also be affected by the observer's personal experience and practice. Therefore, the results cannot be measured using a unified standard because it may differ from person to person [3].

Factors that affect feed intake and appetite may be influenced by a variety of internal and external factors. Internal factors can be physiological, which can be caused by an irregularity in their central nervous system and endocrine system or it can be nutritional factors due to cholesterol, fat, protein, and vitamins. External factors can be environmental, which are water temperature, dissolved oxygen, salinity, and light, or it can be due to management 
factors such as feeding frequency, feeding rate, and feeding time. It is necessary to consider these factors when developing proper equipment for production management and feed intake estimation [2]. Hence, determining when to start and stop feeding plays a crucial role as the effectiveness of the feeding control method directly affects the feed conversion rate and breeding and is very substantial for the reduction of costs and improvement of the welfare of the fish [4]. Also, there is an imperative necessity of developing feeding controls that are adaptive to environmental conditions or growth status [1]. There is a need for automation which is even mentioned in the Comprehensive National Fisheries Industry Development Plan 2016-2020 of the Bureau of Fisheries and Aquatic Resources (BFAR) of the Philippines. In that plan, it was stated that the avenue to development is through automation and mechanization, which leads to the reduction of uncertainties caused by human errors.

The need for automation in terms of feeding the fish is known to almost everyone in the Aquaculture Industry that is why researchers and engineers have developed automatic fish feeders. This development of fish feeders is an example of enhanced innovation to improved aquaculture practices by making it less laborious for the owner or farmer. The inclusion of a fish feeder as one of the inputs of production has significantly reduced labor requirement since feeds are dispensed at a scheduled time [5].

Existing research studies which have developed automated fish feeders include the prototype made by [6], wherein a microcontroller was used to regulate the dispersion of feeds in an aquarium where the owner can use a keypad to set the time of distribution. A smart fish feeder was also made by [7] which operates depending on the fish population, the number of feeds, and the time interval between each feeding. It utilized a GSM module which notified the owner when the tank needed cleaning. Most of the fish feeders that are currently developed are time-based and remote-controlled. Although it solves the issues of manual feeding being timeconsuming and laborious, it still does not solve the problem of underfeeding and overfeeding. These issues can only be solved if all the parameters that should be considered when feeding the fish are really considered.

This study developed an automated fish feeding machine which was created to serve as a solution to the problems faced in fish farms. Among the issues that the machine solve are feed wastage, and fish kills due to underfeeding and overfeeding; natural disturbances during feeding which disrupts the behaviour and activity of fishes; and untimely dispersion of feeds. This feeding machine will automatically control the feeding routine of fish by checking four parameters that will serve as a prerequisite before dispensing the required amount of commercial feeds on the scheduled time of feeding. The parameters to be checked are time, precipitation, the water temperature of the pond, and fish activity. The used of these four parameters were not yet ventured on existing fish feeding machines that mostly uses time in determining when to feed the fish. The device is also capable of notifying the owner or caretaker via text message if fishes have been fed successfully or not and if the level of the feeds is low. These notification points are more substantial than that of previous studies.

The implementation of this study will significantly benefit fish farmers as well as other organizations and companies in the aquaculture industry. It will serve as an excellent innovation for the Bureau of Fisheries and Aquatic Resources (BFAR) as it will also improve the economic productivity and profitability of fishery businesses in the country. This study will be of outstanding contribution to the aquaculture industry and will serve as a stepping stone towards discovering other innovations.

\section{LITERATURE SURVEY}

In the pursuit of creating an automated fish feeding machine that will significantly contribute in solving the problems brought about by manual feeding, many researchers all over the world have developed their fish feeding machine with different kind of features.

A smart fish feeder was made [7] which operates depending on the fish population, the number of feeds, and the time interval between each feeding. It utilized a GSM Module which notified the owner when the tank needed cleaning. An LCD and keypad were also used for the required values. A solenoid valve was used in the dispersion of feeds.

Also, a device was developed, which could dispense dried fish feed [8] in different forms like pellets, sticks, or tablets into ponds or tanks in a controlled and timely manner. It was controlled by a digital timer and dispensed feed according to the set schedule. It has a feeding rate of 250 grams per minute. The device was also adjustable to the owner's desired height, and the size of the hopper can be changed to accommodate various feed capacities.

Since feeding processes were done in Nigeria manually, an automated fish feeder was developed [9] to solve the problem associated with aquaculture. The device dispensed feeds according 
to a predetermined time and could distribute 420 grams every 90 seconds. The device was electrically powered and had a maximum shaft speed of 250 rpm.

Meanwhile, a study which created a fish feeding machine that focused on feed dispensing [10] was also made. The fish feeding machine made use of the stepwise rotation of a stepper motor for the precise dispersion of feeds in a predetermined time which saves labour time. It also helped in scattering the feed across the water pond.

In another fish feeder previously developed [5], they utilized a GSM Module which will give a warning to the owner through Short Messaging Service or SMS to put new feeds into the storage after the feedback system senses that feeds level was low. They say that this will be an advantage for those owners who will be away from ponds since the device could operate on its own.

\section{METHODS}

The four parameters or conditions that are used in the study are based on the feeding patterns of Tilapia. These parameters, along with its significant details, are based on literature review and interview on fish farmers from an aquaculture farm located at the locality of the researchers. The parameters to be satisfied in this fish feeding machine are timely feeding; no occurrence of rain in the time of feeding; water temperature must be less than 40 degrees Celsius, and fishes should be active in the time of feeding.

The feeding frequency used in the machine is three times a day since fish fed three meals had significantly higher gross energy and lipid and lower crude protein contents [11] than fish fed in other frequencies. The feeding time was set to 8:00 AM, 12:00 NOON, and 4:00 PM patterned to the manual feeding time of the aquaculture farm in the locality of the researchers.

The machine will not dispense feeds when raining because this was suggested by animal sciences experts [12] and also the fish farmers interviewed in the study. It will also not dispense feeds when the temperature is high because greater than $32^{\circ} \mathrm{C}$ results in reduce feeding efficiency [13]. Although $32^{\circ} \mathrm{C}$ was suggested in a previous study, the fish farmers interviewed argued that their baseline temperature is $40^{\circ} \mathrm{C}$. Therefore, $40^{\circ} \mathrm{C}$ was set as the default maximum temperature in the machine. The maximum temperature can be easily configured on the interface unit of the machine based on the judgement of the user of the machine.
The last parameter, which was also used to determine if feeds will be dispensed, was based solely on the interview with the fish farmers. They say that when fish is constantly moving in the pond, it means that they are hungry.

\section{A. Electronic Design and Specifications}

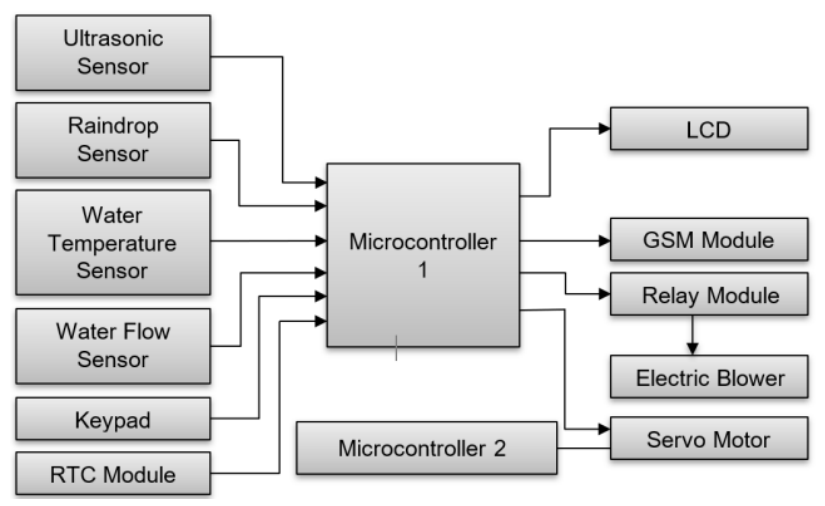

Figure 1. The block diagram of the electronic components of the tetra-parameter fish feeding machine

The fish feeding machine is consists of different electronic devices and components, as shown in Figure 1. The RTC module, raindrop sensor, water temperature sensor, and water flow sensor were used to check the feeding time, occurrence of rain, water temperature, and fish activity, respectively. The keypad and Liquid Crystal Display (LCD) make up an interface unit where the max temperature and required amount of commercial feeds to be dispensed is inputted. An ultrasonic sensor monitors the amount of feeds left. The GSM module is used to send notification messages to the user or owner. All of these electronic components are connected on the microcontroller 1, which serves as the primary microcontroller. A secondary microcontroller, microcontroller 2, was used to provide the power needed by a servo motor that controls the release of commercial feeds. The microcontroller 2 can be changed into an external power supply, but for convenience, the microcontroller 2 was used in the machine. When the commercial feeds are released, it is spread with the help of the blower triggered by a relay module. 


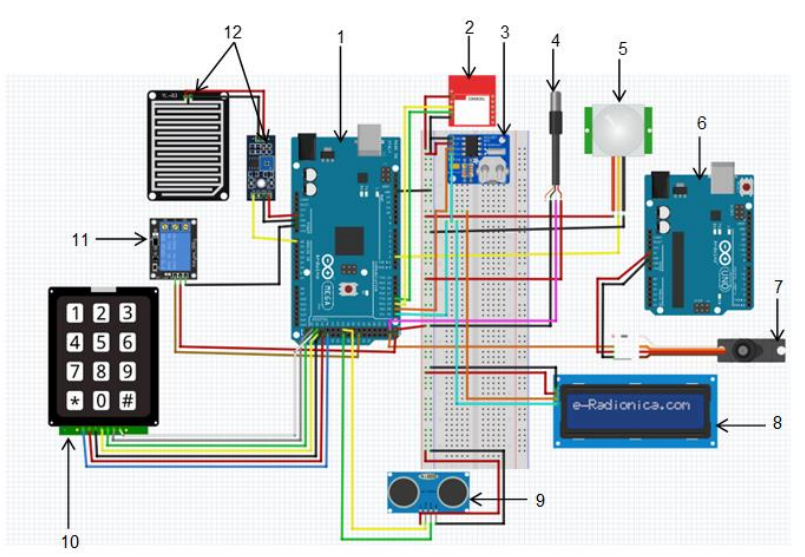

Figure 2. The schematic diagram of the tetraparameter fish feeding machine

The connection of the electronic components of the machine is shown in Figure 2. The Arduino ATmega 2560 (1) is the microcontroller used to control and monitor all the processes of the machine. The RTC module (3), water temperature sensor (4), water flow sensor (5), ultrasonic sensor (9), keypad (10), and raindrop sensor (12) serves as input components which are connected to the digital $\mathrm{I} / \mathrm{O}$ and analog pins of the primary microcontroller. The GSM module (2), servo motor (7), LCD (8), and relay module (11) which serve as the output components of the device are also connected on the digital I/O pins of the microcontroller. The VCC and GND of the different parts except for the servo motor is connected to the primary microcontroller. The servo motor's VCC and GND is connected to the secondary microcontroller (6).

\section{B. Prototype Sketch Design}

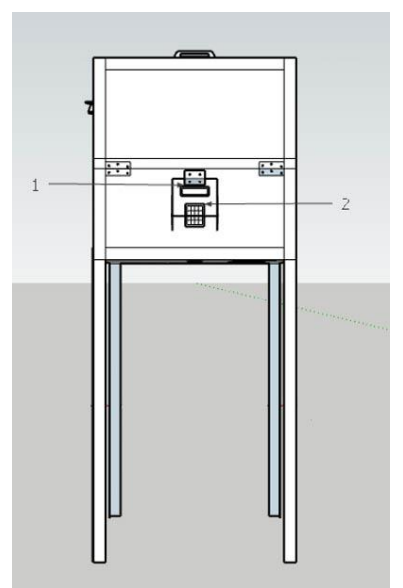

Figure 3. The sketch of the front view of the tetraparameter fish feeding machine

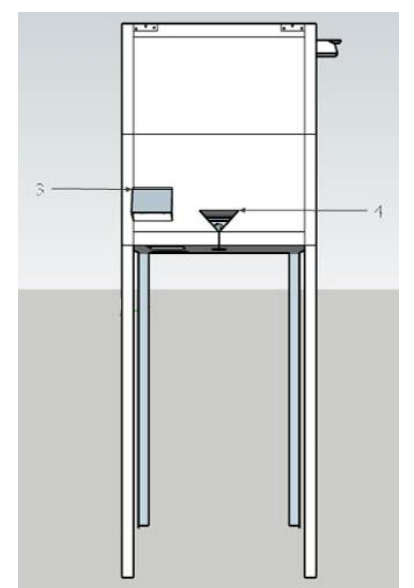

Figure 4. The sketch of the rear view of the tetraparameter fish feeding machine

The front view of the machine as shown in Figure 3 displays the interface unit which is made up of the LCD (1) and keypad (2) while the rear view of the machine as shown in Figure 4 displays the sensor port (3) and the feed outlet (4). Figure 5 shows the left side view of the machine where the wires of the raindrop sensor (7) pass through the wire duct (8). Figure 6 shows the sketch of the water temperature sensor (5) and a box (6) where the water flow sensor is placed. Figure 7 shows where the feed compartment (9), servo motor (10), feed compartment hatch (11), electric blower (12), feed catcher (13), and the feed catcher support (14) are located. Also, the electronic board (15), microcontroller 1 (16), microcontroller (17), relay module (18), raindrop sensor module (19), RTC module (20), and GSM module (21) are shown in Figure 7 which are all placed inside the compartment (22) of the machine.

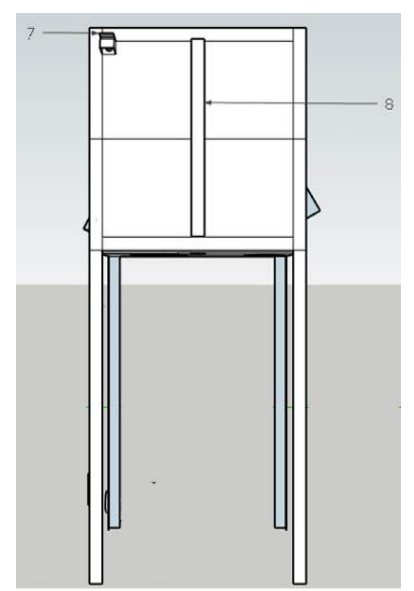

Figure 5. The sketch of left side view of the tetraparameter fish feeding machine 


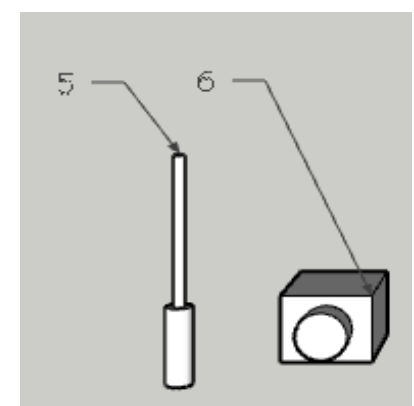

Figure 6. The sketch of the temperature sensor and a box where the water flow sensor is placed

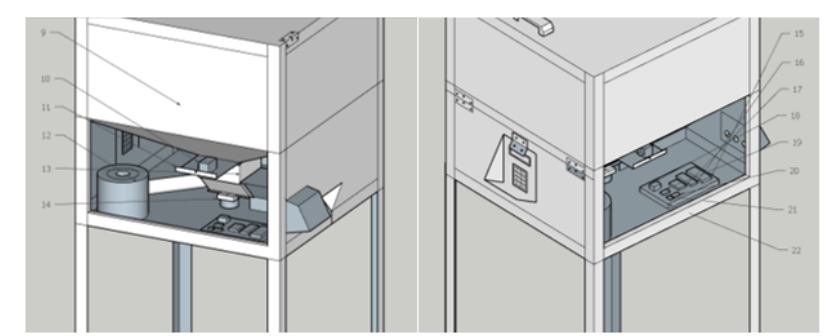

Figure 7. The sketch of the inside view of the tetraparameter fish feeding machine

\section{Feeding Algorithm}
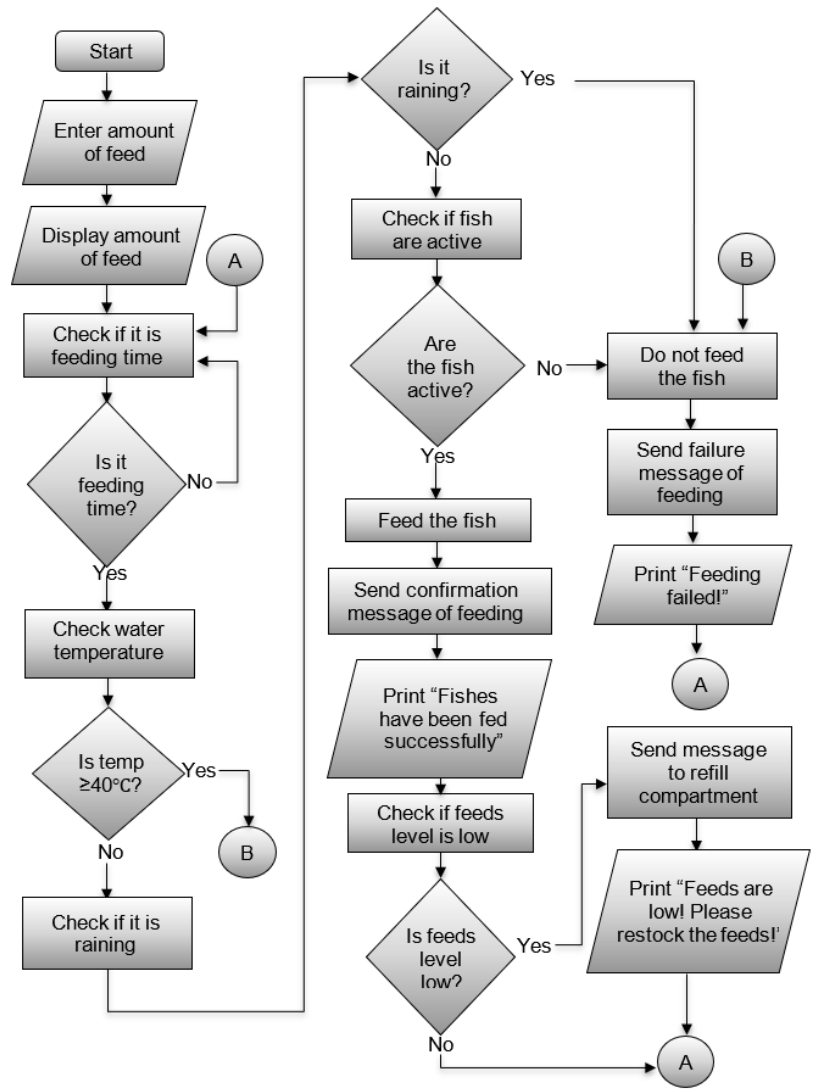

Figure 8. The diagrammatic representation of the algorithm followed by the tetra-parameter fish feeding machine

Before dispensing feeds at the scheduled feeding time, the machine first checks if all the parameters for feeding are satisfied, as seen in the flowchart in Figure 8. To start using the machine, the user will first input the desired amount of feed to be dispensed. After inputting the desired amount of feed which will be displayed in the LCD, all the parameters will be checked. The first parameter to be checked is the time of feeding. When the scheduled time has come for feeding, the second parameter is checked, which is the water temperature. If the water temperature is $40^{\circ} \mathrm{C}$ and above, it is not advisable to feed the fishes for the extreme heat will cause stress to the fish and therefore will result in a fish kill. Thus, the fish feeder will not dispense feeds. The next parameter to be checked is precipitation. When it is raining, the fish tend to refrain from eating, which is why the feeder will not dispense feed once the rain is detected. The last parameter to be checked is the water activity which is monitored throughout the day. When the fish activity is high, the system will dispense feeds; otherwise, it will not. If all parameters are satisfied, only then will the system dispense feeds. A notification message will be sent to the owner when feeding is successful or failed, and when the level of the feeds is low.

The amount of feed dispensed is controlled by the servomotor. The servomotor is opened for the right amount of time to attain the amount of feed required.

$$
T_{0}=\frac{F_{r}}{68 \text { grams }}
$$

The equation (1) aims to compute for the time in seconds that the servomotor is open $\left(\mathrm{T}_{0}\right)$ by dividing the required amount of feeds in grams $\left(\mathrm{F}_{\mathrm{r}}\right)$ which is less than or equal to 150 grams to a constant of 68 grams per second. 


\section{Notification Points}

The machine will send notifications to the user via the GSM module. The fish feeding machine has 3 Decision Points (DP) of message notifications.

- DP1: Successful Feeding - when all the parameters are satisfied, the machine will send a notification message reading, "Fishes have been fed successfully".

- DP2: Unsuccessful Feeding - when one of the parameters is not satisfied, the machine will send a notification message reading, "Feeding failed!".

- DP3: Low Feed Level - when the ultrasonic sensor alerts the microcontroller that the feed level is low, the machine will send a notification message reading, "Feeds are low! Please restock the feeds!"

\section{RESULTS AND DISCUSSION}

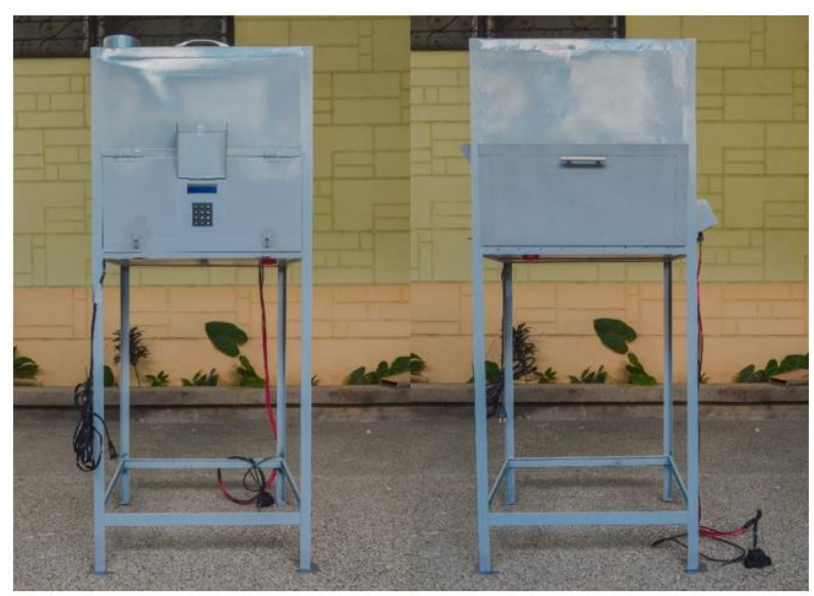

Figure 8 . The actual prototype of the tetra-parameter fish feeding machine

The actual prototype of the fish feeding machine is shown in Figure 8. The body of the machine is made of a $0.7 \mathrm{~mm}$ thick G.I. sheet, and the frame is made of $25 \times 25 \times 1 \mathrm{~mm}$ angle bar. Both materials are chosen and welded together because it will give enough strength for the machine to hold the fish feed and durability for outdoor use. The body and frame of the machine are painted with a silver primer with a polymer component to protect it from the elements that cause corrosion, and the light color helps minimize the absorption of heat from the sun. The machine's cube-like geometry is purposely designed for ease of construction and is raised 75 centimeters from the ground to offset the trajectory of the feeds coming out of the feed outlet.

The feed outlet and feed catcher are designed in an inverted triangle to situate the feeds in a centered position relative to the electric blower for efficient dispersion of feeds. The machine has a hatch at the front and right side to easily access the electronic components and another hatch on the top for the feed compartment. Given the outdoor use of the machine, electronic components are covered for protection to rain and direct sunlight. The machine has two holes at the bottom: the small hole on the left corner is for the pathway of the electrical plug and the large hole on the right is for the intake of the electric blower.

Several tests were conducted to check if the machine work based on how it was programmed. The first test run was to determine if feeding will take place or not based on the checked parameters. Here, the machine was brought to an aquaculture farm. Unfortunately, during the testing, there was no rain, so to check on the precipitation parameter, the researchers simulated rain by using water host. Also, in the aquaculture farm during the time of the testing, the water temperature never goes beyond 40 degrees Celsius. So, the researchers place the temperature sensor in warm water to check on the temperature parameter.

Table 1 shows the action of the feeding machine dependent on the parameters checked. The machine checked first the water temperature of the pond. When the water temperature exceeded $40^{\circ} \mathrm{C}$, the operation of the machine was terminated, meaning it did not dispense feeds. On the other hand, when the temperature was below $40^{\circ} \mathrm{C}$, the machine proceeded to check the next parameter, which is precipitation. When the machine detected rain, the operation was terminated. When there was no occurrence of rain, the machine proceeded to check the next parameter, which is the fish activity which determined when the fishes are active or passive. When all the parameters were satisfied, the machine released feeds, but when at least one of the parameters was not satisfied, the machine did not release feeds. This scenario proves that the fish feeding machine functions well in feed dispersion after reading the parameters.

Table 1 . The feed dispensing activity of the tetraparameter fish feeding machine based on the parameters checked

\begin{tabular}{|c|c|c|c|c|}
\hline $\begin{array}{c}\text { Test } \\
\text { No. }\end{array}$ & Temperature & Precipitation & $\begin{array}{c}\text { Fish } \\
\text { Activity }\end{array}$ & $\begin{array}{c}\text { Dispensed } \\
\text { Feeds }\end{array}$ \\
\hline 1 & $27.18^{\circ} \mathrm{C}$ & $\mathbf{X}$ & $\checkmark$ & Yes \\
\hline 2 & $27.18^{\circ} \mathrm{C}$ & $\mathbf{X}$ & $\checkmark$ & Yes \\
\hline 3 & $27.17^{\circ} \mathrm{C}$ & $\mathbf{X}$ & $\checkmark$ & Yes \\
\hline 4 & $27.16^{\circ} \mathrm{C}$ & $\mathbf{X}$ & $\checkmark$ & Yes \\
\hline 5 & $27.16^{\circ} \mathrm{C}$ & $X$ & $\checkmark$ & Yes \\
\hline 6 & $27.16^{\circ} \mathrm{C}$ & $\checkmark$ & ---- & No \\
\hline
\end{tabular}




\begin{tabular}{|c|c|c|c|c|}
\hline 7 & $27.16^{\circ} \mathrm{C}$ & $\checkmark$ & ----- & No \\
\hline 8 & $27.15^{\circ} \mathrm{C}$ & $\checkmark$ & ---- & No \\
\hline 9 & $27.15^{\circ} \mathrm{C}$ & $\checkmark$ & ---- & No \\
\hline 10 & $27.15^{\circ} \mathrm{C}$ & $\checkmark$ & ----- & No \\
\hline 11 & $42.87^{\circ} \mathrm{C}$ & ---- & ---- & No \\
\hline 12 & $42.85^{\circ} \mathrm{C}$ & ----- & ----- & No \\
\hline 13 & $42.80^{\circ} \mathrm{C}$ & ----- & ---- & No \\
\hline 14 & $42.75^{\circ} \mathrm{C}$ & ---- & ---- & No \\
\hline 15 & $42.69^{\circ} \mathrm{C}$ & ----- & ----- & No \\
\hline 16 & $27.19^{\circ} \mathrm{C}$ & $\boldsymbol{X}$ & $\boldsymbol{X}$ & No \\
\hline 17 & $27.18^{\circ} \mathrm{C}$ & $\boldsymbol{X}$ & $\boldsymbol{X}$ & No \\
\hline 18 & $27.18^{\circ} \mathrm{C}$ & $\boldsymbol{X}$ & $\boldsymbol{X}$ & No \\
\hline 19 & $27.18^{\circ} \mathrm{C}$ & $\boldsymbol{X}$ & $\boldsymbol{X}$ & No \\
\hline 20 & $27.17^{\circ} \mathrm{C}$ & $\boldsymbol{X}$ & $\boldsymbol{X}$ & No \\
\hline
\end{tabular}

Numerous research studies have been made in the past, but most of them focused only on timely feeding. The advantage of the machine as endorsed in this paper is the utilization of the different sensor which are raindrop sensor, water temperature sensor, and water flow sensor to check the various parameters which are lacking in past studies [5-10].

The next test conducted was to determine if the machine dispenses the correct amount of required commercial feeds. This test was conducted through lab testing. The feeds distributed by the machine is collected and then weighed using a weighing device.

Table 2 shows the comparison between the required weight of the feeds to be dispensed as entered by the fish farmer to the actual weight of feeds dispensed by the machine through the aid of the servomotor. Dispensed feeds were measured through the aid of a digital weighing scale. After 20 trials wherein five trials, each was conducted for 50 grams, 80 grams, 100 grams, and 150 grams; the fish feeding machine was able to dispense feeds close to the required weight of feeds as entered which proves that the fish feeder is accurate in releasing the right amount of feeds.

Table 2. The accuracy of the tetra-parameter fish feeding machine in dispensing the required feeds

\begin{tabular}{|c|c|c|c|}
\hline $\begin{array}{c}\text { Test } \\
\text { No. }\end{array}$ & $\begin{array}{c}\text { Required Weight } \\
\text { to be Dispensed } \\
\text { (in } g \text { ) }\end{array}$ & $\begin{array}{c}\text { Actual Feed } \\
\text { Dispensed } \\
\text { (in } g \text { ) }\end{array}$ & $\begin{array}{c}\text { Accuracy } \\
\text { Percentage } \\
(\%)\end{array}$ \\
\hline 1 & 50 & 49.89 & 99.78 \\
\hline 2 & 50 & 47.17 & 94.34 \\
\hline 3 & 50 & 47.45 & 94.90 \\
\hline 4 & 50 & 49.02 & 98.04 \\
\hline 5 & 50 & 47.13 & 94.26 \\
\hline 6 & 80 & 82.08 & 97.40 \\
\hline 7 & 80 & 83.81 & 95.24 \\
\hline 8 & 80 & 83.81 & 95.24 \\
\hline 9 & 80 & 82.63 & 96.71 \\
\hline 10 & 80 & 83.36 & 95.80 \\
\hline 11 & 100 & 104.39 & 95.61 \\
\hline 12 & 100 & 103.95 & 96.05 \\
\hline 13 & 100 & 104.38 & 95.62 \\
\hline 14 & 100 & 103.42 & 96.58 \\
\hline
\end{tabular}

\begin{tabular}{|l|l|l|l|}
\hline 15 & 100 & 102.51 & 97.49 \\
\hline 16 & 150 & 153.76 & 97.49 \\
\hline 17 & 150 & 154.66 & 96.89 \\
\hline 18 & 150 & 152.96 & 98.03 \\
\hline 19 & 150 & 152.01 & 98.66 \\
\hline 20 & 150 & 151.32 & 99.12 \\
\hline
\end{tabular}

Table 3. The message and time it takes to receive a message after a decision point is reached

\begin{tabular}{|c|c|c|}
\hline $\begin{array}{l}\text { Test } \\
\text { No. }\end{array}$ & Message & Time $(s)$ \\
\hline 1 & Fishes have been fed successfully. & 7.37 \\
\hline 2 & Fishes have been fed successfully. & 6.77 \\
\hline 3 & Fishes have been fed successfully. & 5.67 \\
\hline 4 & Fishes have been fed successfully. & 7.54 \\
\hline 5 & Fishes have been fed successfully. & 6.40 \\
\hline 6 & Fishes have been fed successfully. & 6.51 \\
\hline 7 & Fishes have been fed successfully. & 5.87 \\
\hline 8 & Fishes have been fed successfully. & 5.62 \\
\hline 9 & Fishes have been fed successfully. & 7.51 \\
\hline 10 & Fishes have been fed successfully. & 7.48 \\
\hline 11 & Feeding failed! & 4.09 \\
\hline 12 & Feeding failed! & 4.89 \\
\hline 13 & Feeding failed! & 5.87 \\
\hline 14 & Feeding failed! & 4.71 \\
\hline 15 & Feeding failed! & 4.39 \\
\hline 16 & Feeding failed! & 5.13 \\
\hline 17 & Feeding failed! & 5.09 \\
\hline 18 & Feeding failed! & 6.11 \\
\hline 19 & Feeding failed! & 4.29 \\
\hline 20 & Feeding failed! & 4.89 \\
\hline 21 & Feeds are low! Please restock the feeds! & 7.52 \\
\hline 22 & Feeds are low! Please restock the feeds! & 7.07 \\
\hline 23 & Feeds are low! Please restock the feeds! & 6.87 \\
\hline 24 & Feeds are low! Please restock the feeds! & 6.06 \\
\hline 25 & Feeds are low! Please restock the feeds! & 7.62 \\
\hline 26 & Feeds are low! Please restock the feeds! & 7.51 \\
\hline 27 & Feeds are low! Please restock the feeds! & 6.05 \\
\hline 28 & Feeds are low! Please restock the feeds! & 6.21 \\
\hline 29 & Feeds are low! Please restock the feeds! & 5.52 \\
\hline 30 & Feeds are low! Please restock the feeds! & 5.43 \\
\hline
\end{tabular}

Tables 3 shows the notifications received by the owner during testing. After conducting 30 trials, ten each for every type of notification, the fish feeding machine was able to send notifications within 10 seconds if the signal is fine, which proves its timeliness. The addition of notification messages through GSM Module in the fish feeding machine will benefit fish farmers much, especially those who are away from their ponds since the device can operate on its own. This statement was supported in the study made by [5][7]. 


\section{CONCLUSION}

After conducting several trials of the different parameters and of the notification system, the machine was able to implement the capabilities of the manual process of feeding done by a fish farmer. The machine dispensed the required weight of feeds after satisfying the parameters which are time, water temperature, precipitation, and fish activity which addresses the problems regarding underfeeding, and overfeeding. The fish feeder was also reliable in terms of sending notifications to the owner through SMS since results convey that notifications are received within 10 seconds if the signal is fine. With the results portrayed by the tetra-parameter fish feeding machine, it is considered to be reliable since it exhibits the capabilities of a fish farmer in decision making when it comes to dispersion of feeds.

For the benefit of the users of this feeder, the researchers recommend that they must have a good grasp on the basics and proper way of operating the system for them to prevent inconvenience while using it. If the fish feeder is intended for large-scale ponds, the compartment of the feeds must be made larger and durable for heavier weight. One can also make the prototype a self-sustaining machine by drawing power from solar panels. Creating a smartphone application that will serve as the user interface of the entire machine via Bluetooth is also recommended. Adding a weight sensor can also provide the more precise and exact amount of feeds to be released and using infrared proximity sensor instead of the ultrasonic proximity sensor can also provide a better quality of distance measurement. One may also incorporate a cooling system such as an exhaust fan or heat sink.

\section{References:}

[1] Chao Zhou, Daming Xu, Kai Lin, Chuanheng Sun, and Xinting Yang, Intelligent feeding control methods in aquaculture with an emphasis on fish: a review, Reviews in Aquaculture, Vol. 10, No. 4, 2018, pp. 975-993.

[2] Min Sun, Shahbaz Hassan, and Daoliang Li, Models for estimating feed intake in aquaculture: a review. Computers and Electronics in Agriculture, Vol. 127, 2016, pp. 425-438.

[3] Ziyi Liu, Xian Li, Liangzhong Fan, Huanda Lu, Li Liu, and Ying Liua, Measuring feeding activity of fish in RAS using computer vision, Aquacultural Engineering, Vol. 60, 2014, pp. 20-27.

[4] Martin Fore, Morten Alver, Jo Arve Alfredsen, Giancarlo Marafioti, Gunnar Senneset, Jens Birkevold, Finn Victor Willumsen, Guttorm Lange, Asa Espmark, and Bendik Fyhn Terjesen, Modelling growth performance and feeding behaviour of Atlantic salmon (Salmo salar L.) in commercial-size aquaculture net pens: Model details and validation through full-scale experiments, Aquaculture, Vol. 464, 2016, pp. 268278.

[5] Noori Abdul-nabi Nasir and Quesy Hamed, Growth development of young common carp Cyprinus carpio through dietary sodium chloride supplementation. Mesopotamia Environmental Journal. Vol. 2, 2016, pp. 12-18.

[6] Mohammad Abdul Hye, Md Manjurul Akter, Atiq Mohammad Jahangir, and Hasan Zaman, A Novel Design and Implementation of Automated Feeding Mechanism in Fish Aquariums. In 2018 2nd International Conference on Electronics, Materials Engineering \& Nano-Technology, 2018, pp. 1-7.

[7] Akilesh Sabari, V. Savitha, N. Vinithra, and J. Dhanasekar, Smart Fish Feeder, International Journal of Scientific Research in Computer Science, Engineering and Technology, Vol. 2, No. 2, 2017, pp. 111-115.

[8] S. J. Yeoh, F. S. Taip, J. Endan, R.A. Talib and M.K. Siti Mazlina, Development of automatic feeding machine for aquaculture industry, Pertanika Journal of Science and Technology, Vol. 18, No. 1, 2010, pp. 105-110.

[9] O.C. Osueke, Olayanju Adeniyi Tajudeen, Anthony Onokwai, and P. Uzendu, Design and Construction of an Automatic Fish Feeder. International Journal of Mechanical Engineering and Technology, Vol. 9, No. 10, 2018, pp. 1631-1645.

[10] Ragini Swarnakar, Aruna Jayarajan, Sakshi Nirwan, and Prakruti Shah, The developement of automatic fish feeder system using arduino UNO, International Journal of Modern Trends in Engineering and Research, Vol. 4, No. 7, 2017, pp. 64-68.

[11] Marty Riche, Michael Oetker, David I. Haley, Tiffany Smith, and Donald L. Garling, Effect of feeding frequency on consumption, growth, and efficiency in juvenile tilapia (Oreochromis 
niloticus), The Israeli Journal of Aquaculture Bamidgeh, Vol. 56, No. 4, 2004, pp. 247-255.

[12] Chandigarh News, Farmers must take special care of fish during rainy season: Gadvasu experts, The Times of India, 2018.

[13] N. P. Pandit and M. Nakamura, Effect of high temperature on survival, growth and feed conversion ratio of Nile tilapia, Oreochromis niloticus, Our Nature, Vol. 8, No. 1, 2010, pp. 219224.

Contribution of individual authors to the creation of a scientific article (ghostwriting policy)

Author Contributions: Please, indicate the role and the contribution of each author:

Ertie Abana has conceptualized the research and organize the research paper.

Maureen Baricaua investigated the parameters that was used in the feeding machine.

Rochelled Joyce Casibang made the literature review.

Aldene Paulino Babara drawn the sketch of the machine. Vincent Joseph Gaspar written the program of the machine.

Fritz Gerald Puzon lead the construction of the machine.

Follow: www.wseas.org/multimedia/contributor-role-

instruction.pdf

Sources of funding for research presented in a scientific article or scientific article itself

Report potential sources of funding if there is any

\section{Creative Commons Attribution License 4.0} (Attribution 4.0 International, CC BY 4.0)

This article is published under the terms of the Creative Commons Attribution License 4.0

https://creativecommons.org/licenses/by/4.0/deed.en_US 